\title{
P-0427- WHITE TEA HAS BETTER ANTIOXIDATIVE, ANTIDIABETIC AND ANTIOBESOGENIC PROPERTIES THAN GREEN AND BLACK TEA
}

Rebecca Reddy and Md. Shahidul Islam*

Department of Biochemistry, School of Life Sciences, University of KwaZulu-Natal, Durban 4000, South Africa

\section{INTRODUCTION}

Diabetes mellitus (DM) is the most prevalent endocrine disorder in humans. Current anti-diabetic therapy is based on synthetic drugs that very often have side effects. Recently, natural products have become attractive alternatives to synthetic drugs. However, many cases, very little is known about the mechanism of action of these anti-diabetic plants. Decrease in postprandial hyperglycemia by inhibition of intestinal glucose absorption is a vital target in T2D therapy. This is achieved by inhibition of two key carbohydrate metabolizing enzymes $\alpha$-amylase and $\alpha$-glucosidase. Herbal teas are recognized for their phenolic content, which contributes to their anti-oxidant activities. These compounds present in tea reduce the risk of a variety of diseases (Yang et al., 2009). Teas are a rich source of flavonoids, polyphenols and catechins, which all have potential anti-oxidative free radical scavenging and anti-diabetic activities (Sharangi, 2009).

\section{METHODS}
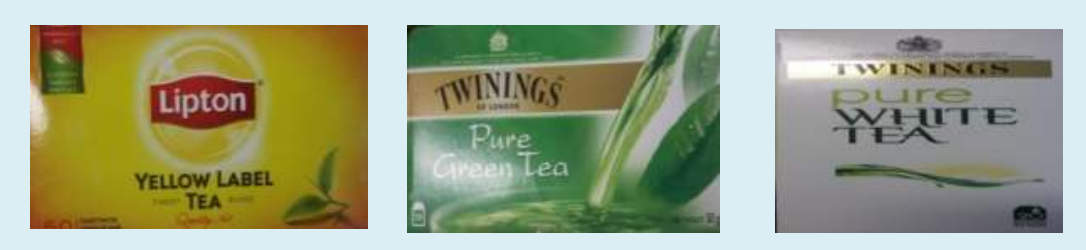

Aqueous extracts of the black, green and white teas were prepared and subsequently analyzed for their total phenolic contents; antioxidant activity vis-àvis 2,2-diphenyl-1-picrylhydrazyl (DPPH) scavenging activity and ferric reducing ability (FRAP); inhibition of $\alpha$-amylase and $\alpha$ glucosidase enzymes activity in vitro. The extracts were also investigated for their role in the inhibition of intestinal glucose absorption in isolated rat jejunum and glucose uptake.

\section{STATISTICAL ANALYSIS}

All data are presented as mean $\pm \mathrm{SD}$. Data were analyzed using a statistical software package (SPSS for windows, USA), by using one-way ANOVA and Tukey's HSD post hoc test. Values were considered significantly different at $p<0.05$. $a b c$ Different alphabets over the bars for a given concentration for each extract are significantly different from each other.

\begin{tabular}{|l|c|}
\hline \multicolumn{2}{|c|}{ RESULTS } \\
\hline $\begin{array}{l}\text { Table 1: Total Polyphenol Content as Gallic } \\
\text { Acid equivalent (\%) }\end{array}$ \\
\hline Black Tea & $84.57 \pm 0.241^{\mathrm{a}}$ \\
\hline Green Tea & $112.50 \pm 0.029^{\mathrm{b}}$ \\
\hline & $133.75 \pm 0.034^{\mathrm{c}}$ \\
\hline
\end{tabular}

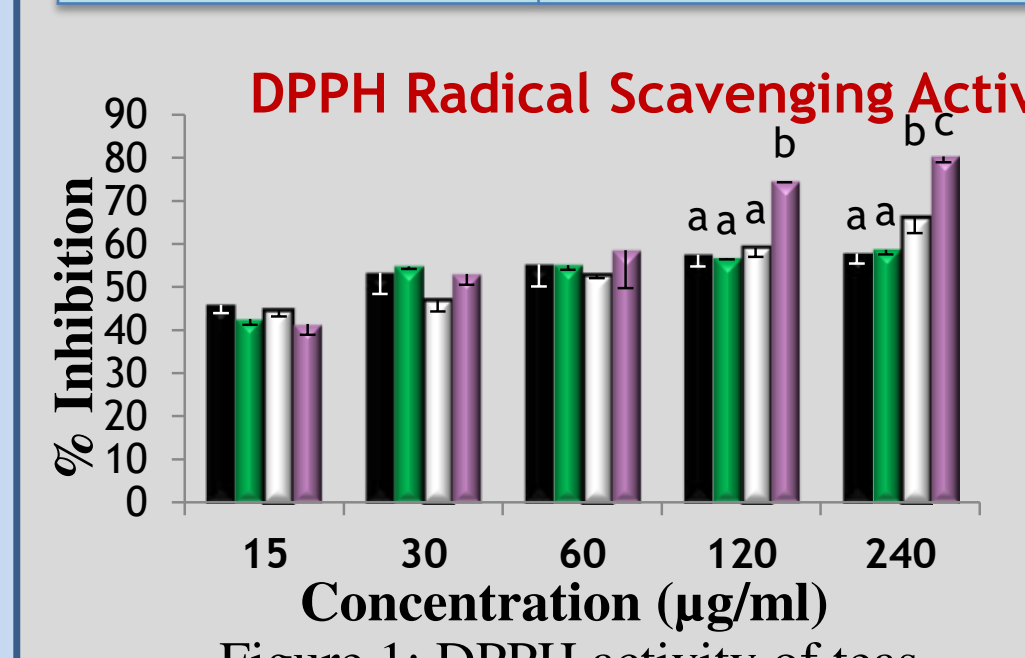
QWT

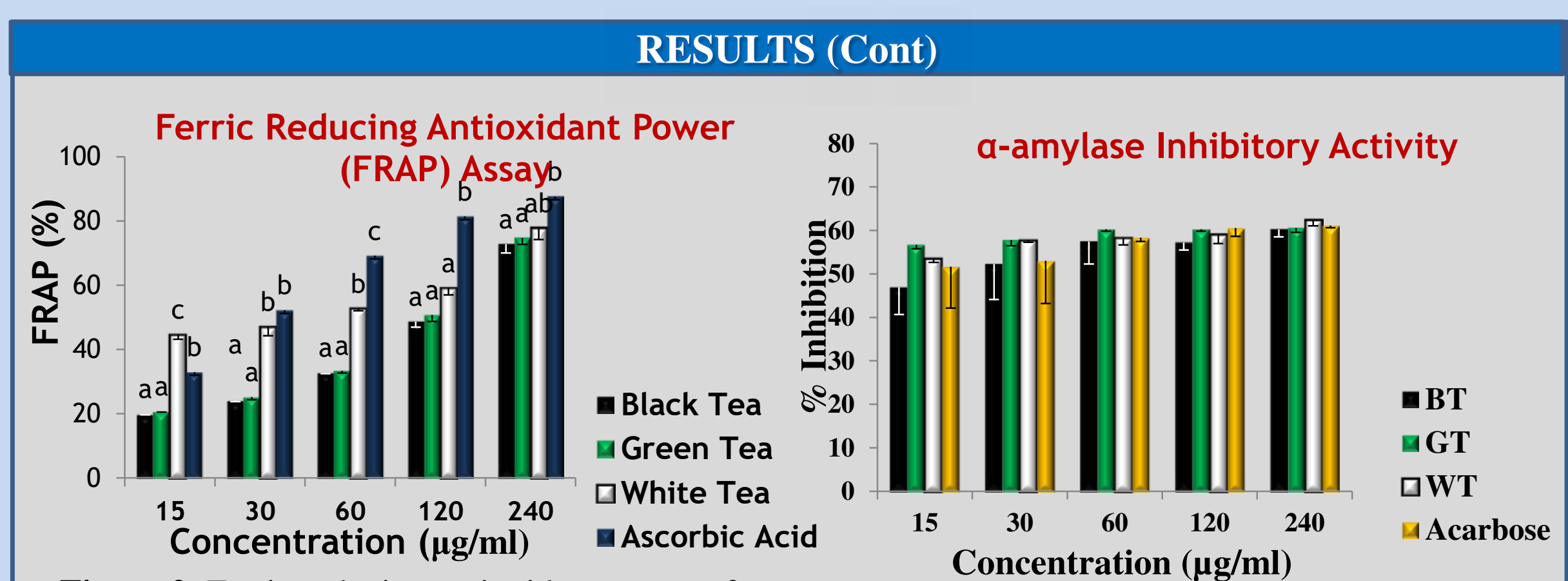

Figure 2: Ferric reducing antioxidant power of BT, GT, WT extracts and Standard

Figure 3: Graph showing the effect of BT, GT and WT on activities of alpha amylase enzyme in vitro.
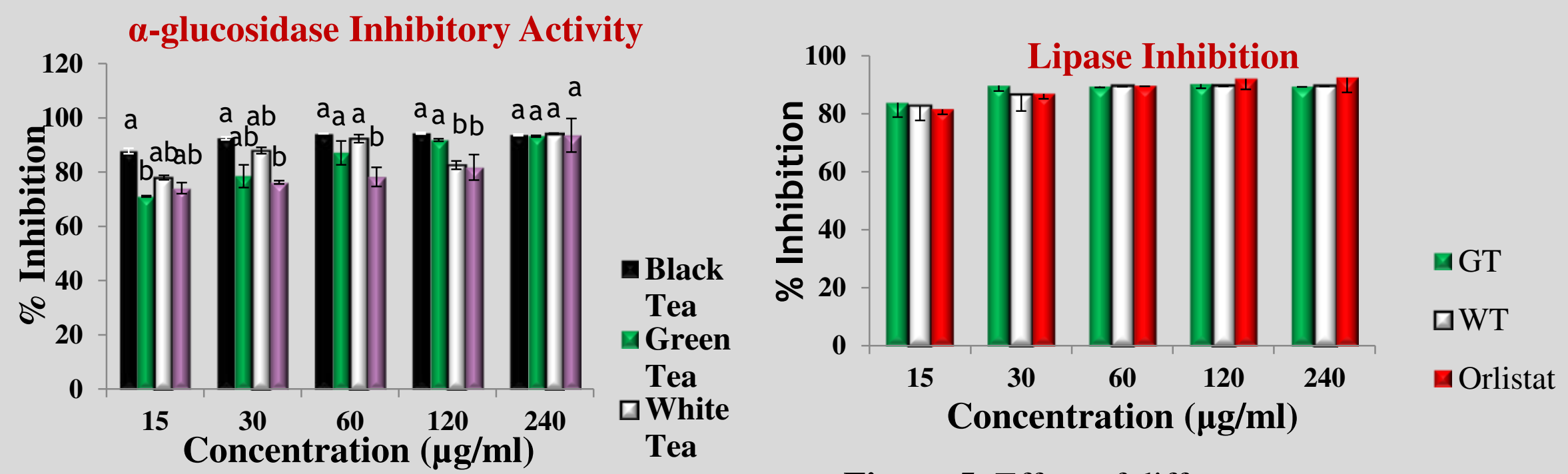

Figure 4: Effects of different tea extracts on alpha glucosidase enzyme activity in vitro

Figure 5: Effect of different tea extracts on activity of lipase enzyme activity in vitro

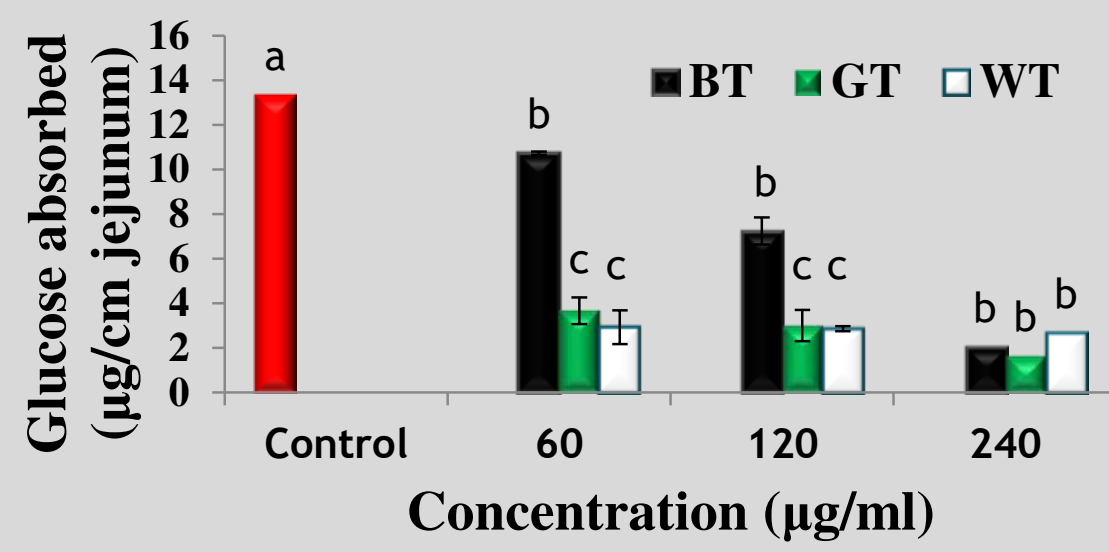

Figure 6: Graph showing the effects of BT, GT and WT on glucose absorption in isolated rat jejunum.

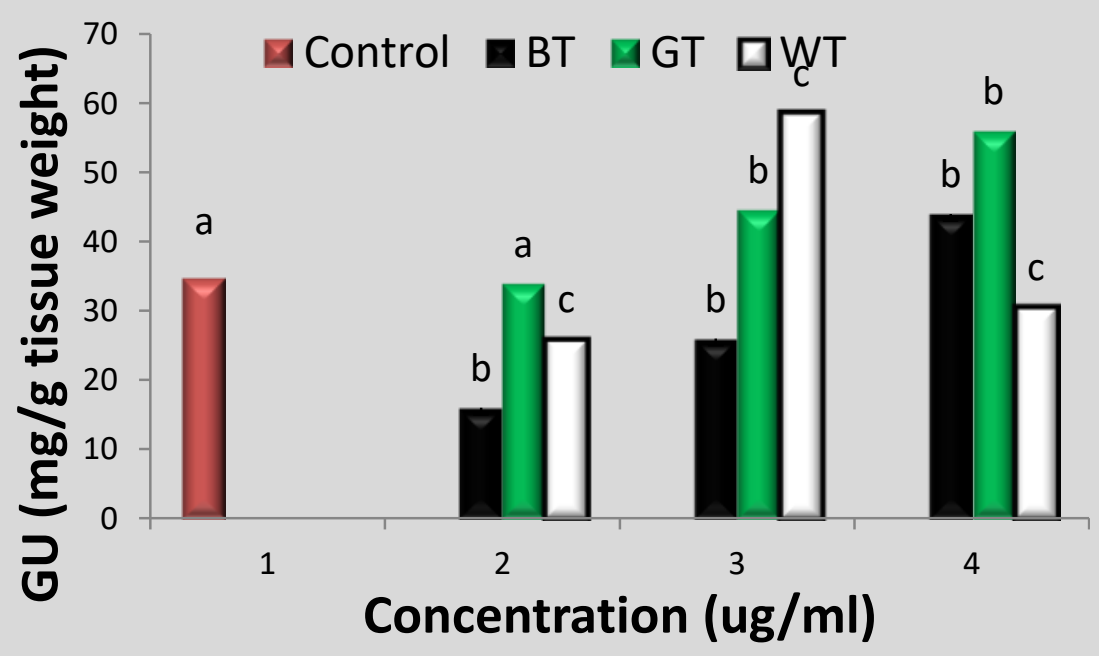

Figure 6: Graph showing the effects of BT, GT and WT on glucose uptake in rat psoas muscle

\begin{tabular}{|c|c|c|c|c|}
\hline \multicolumn{5}{|r|}{ CONCLUSION } \\
\hline \multicolumn{4}{|c|}{ Summary of results } & \multirow{7}{*}{$\begin{array}{l}\text { It is possible to conclude from this study that white tea has } \\
\text { higher antioxidant activity that could be attributed to its } \\
\text { higher total phenol. White tea also possessed higher anti- } \\
\text { diabetic properties, followed by green tea and black tea, } \\
\text { indicating potential anti-hyperglycemic properties. Green } \\
\text { tea and white tea showed strong inhibition of lipase, } \\
\text { therefore such beverages, could find use as natural therapy } \\
\text { to control lipids levels and obesity. }\end{array}$} \\
\hline ASSAY & BT & GT & WT & \\
\hline DPPH & 3 & 2 & 1 & \\
\hline FRAP & 1 & 2 & 3 & \\
\hline Amylase & 1 & 2 & 3 & \\
\hline Glucosidase & 3 & 1 & 2 & \\
\hline Lipase & 1 & 2 & 3 & \\
\hline
\end{tabular}

Glucose

REFERENCES

\begin{tabular}{|l|c|c|c|}
\hline absorption & $\mathbf{1}$ & $\mathbf{2}$ & $\mathbf{3}$ \\
\hline Total SCORE: & 10 & $\mathbf{1 1}$ & $\mathbf{1 5}$ \\
\hline
\end{tabular}

Sharangi, A.B. (2009). Medical and therapeutic potentialities of tea (Camellia sinensis)- A review. Food research international; 42:529-535.

Yang, S.C., Lambert, J.D., and Sang S. (2009). Antioxidative and anti-carcinogenic activities of tea in polyphenols; Arch Toxicol; 83(1):11

Quesille-Villalobos, A., Torrico, J.S., Ranilla, L.G. (2013). Phenolic compounds, antioxidant capacity, and in vitro $\alpha$-amylase inhibitory potential of tea infusions

$\mathrm{HIC}_{50}$ value $=\widehat{C}$ score $\mathrm{WT}>\mathrm{GT}>\mathrm{BT}$

